\title{
PROGRAMA DESIGN EXPORT: INICIATIVA ESTRATÉGICA DE PROMOÇÃO DO DESIGN BRASILEIRO COM FOCO NA EXPORTAÇÃO
}

\author{
Ken Flávio Ono Fonseca \\ Universidade Federal do Paraná \\ ken.fonseca@gmail.com \\ Adriano Heemann \\ Universidade Federal do Paraná \\ adriano.heemann@gmail.com \\ Ana Leocádia de Souza Brum \\ Centro Brasil Design \\ Letícia Castro \\ Centro Brasil Design
}

Resumo: O Programa Design Export é uma ação de promoção de design realizada pela Agência Brasileira de Promoção de Exportações e Investimentos (Apex-Brasil) e coordenada pelo Centro Brasil Design. Teve por objetivo incentivar que empresas brasileiras desenvolvessem produtos e serviços com agregação de valor por meio da inserção do design e da inovação em sua cultura organizacional, visando uma indústria mais competitiva e preparada para o mercado internacional. Este artigo apresenta um melhor entendimento de como se deu a condução desse programa; a identificação de suas etapas e procedimentos de gestão poderá auxiliar e fornecer subsídios para a elaboração de políticas públicas em design e futuros programas focados na inserção do design junto ao setor produtivo.

Palavras-chave: políticas de design, gestão de design, inovação.

\begin{abstract}
The Design Export is a design initiative of the Brazilian Trade and Investment Promotion Agency (Apex-Brasil) and the Brazil Design Centre responsible for its realization. It supports Brazilian companies in the development of products and services with added value through the integration of design and innovation in their organizational culture, towards a more competitive industry aimed at the international market. This article provides a better understanding to the program management, stages and proceedings to provide support for the development of future design public policies and programs focused on design and productive sector integration.
\end{abstract}

Palavras-chave: design policies, design management, innovation. 


\section{INTRODUÇÃO}

No Brasil a pauta de exportação é amplamente dependente de commodities, caracterizados por produção em larga escala e baixo valor agregado (ABDI, 2016); fato reconhecido pelo governo brasileiro que percebe a fragilidade desse modelo econômico que se baseia em produtos com preços voláteis e sujeitos a intervenções públicas e privados. As políticas industriais brasileiras nos últimos 20 anos, como as apresentadas na Política Industrial, Tecnológica e de Comércio Exterior - PITCE do Ministério do Desenvolvimento, Indústria e Comércio Exterior de 2004, tem apontado o claro objetivo de fortalecer e expandir a base industrial brasileira por meio da melhoria da capacidade inovadora das empresas e buscando o aumento também da produção e exportação de produtos de maior valor agregado (PITCE, 2016).

Essas políticas públicas, concebidas a partir de uma visão estratégica de longo prazo, buscam alcançar o aumento de eficiência e da competitividade internacional, nem sempre explicitando o uso do design como estratégia, mas, corroborando com Salerno e Daher (2006), recomendando a transformação da estrutura pela inovação; ou seja, aumentando a intensidade tecnológica dos produtos, certificações, e em especial o design, marca e diferenciação. Em outros documentos, como da Agência Brasileira de Desenvolvimento Industrial - ABDI a importância do design como estratégia de inovação para a competitividade da indústria é mais evidente, transparecendo de forma explícita nas análises e publicações (ABDI, 2016).

Diversas ações desde então vêm sendo realizadas para a promoção e inserção do design junto ao setor produtivo, mais especificamente desde a criação do Programa Brasileiro do Design - PBD no Ministério do Desenvolvimento, Indústria e Comércio Exterior - MDIC; pelo Decreto de 09 de novembro de 1995 (PBD, 2012), quando o design tem oficializada sua inclusão nas políticas públicas de desenvolvimento do Brasil. Em sua criação, há quase vinte anos, já se apontava a necessidade dos empresários brasileiros serem motivados a entender e utilizar o binômio Design e Inovação no sistema produtivo (PBD, 2012); e, entre as suas atribuições, coube ao PBD desenvolver parcerias com agentes econômicos e sociais de organismos governamentais e privados bem como criar novos mecanismos e instrumentos de apoio, fomento e financiamento para o design; o que, porém, não parece ter obtido o seu devido reconhecimento estratégico pelo governo brasileiro. Em sua discussão sobre as políticas públicas de Design no Brasil Patrocínio (2013) apontava que, apesar de existir o PBD, o Brasil não teria efetivamente uma política nacional de design e aparentemente ignorava o real potencial do design enquanto ferramenta para a competitividade.

Em entrevista concedida a Patrocínio e Nunes (2015), Gui Bonsipe comenta como no Brasil os programas nacionais de design tem se limitado a tarefas de promoção de eventos e prêmios, sem interferir nos pontos nevrálgicos da indústria. Corrobora com essa questão também Patrocínio (2016), ao comentar que diferentemente do Brasil, onde até mesmo ações de relativo sucesso foram desmobilizadas, em países mais competitivos como, por exemplo, Reino Unido, Finlândia, Coréia do Sul e Taiwan, o design vem sendo considerado uma ferramenta estratégica imprescindível, incentivada por programas governamentais específicos. Motivo esse que leva países considerados referências para o design como a Dinamarca verificar que $93 \%$ das empresas utilizam design em sua estratégia; em estudo realizado 
pelo governo dinamarquês houve a constatação de que empresas que utilizavam design alcançaram crescimento de até $250 \%$ (WHICHER, 2016).

Um dado relevante, porém, apontado por Patrocínio (2016), refere-se a ações e iniciativas regionais que vem sendo adotadas no Brasil e que merecem destaque mundial, e em especial as desenvolvidas pelo Centro Brasil Design (antigo Centro de Design Paraná) considerado um dos importantes atores nas políticas de design do Brasil (2013).

Diante desse panorama o presente artigo tem por objetivo descrever e explicitar o processo de condução de uma dessas iniciativas: o Programa Design Export - DEX, uma realização da Agência Brasileira de Promoção de Exportações e Investimentos - Apex-Brasil, vinculado ao Ministério das Relações Exteriores (na época vinculada ao Ministério do Desenvolvimento, Indústria e Comércio Exterior) e coordenado pelo Centro Brasil Design - CBD, instituição sem fins lucrativos que atua nacionalmente promovendo o uso e aplicação do design como ferramenta estratégica para o desenvolvimento da competitividade no país (CBD, 2016).

A Apex-Brasil vem ocupando uma posição relevante em prol da disseminação das práticas de design junto ao setor produtivo, já que as rápidas mudanças da dinâmica mundial decorrente do processo de globalização têm impulsionado cada vez mais a implementação de estratégias baseadas em design visando o aumento da competitividade das empresas nacionais frente à concorrência internacional.

$A$ análise aqui descrita enfocou o DEX por ser considerado um programa bem sucedido (APEX, 2016), que teve sua primeira edição entre os anos de 2013 e 2015, citados no Diagnóstico do Design Brasileiro (2014), quando 100 empresas foram apoiadas para o desenvolvimento de soluções em design. É também citado no Plano Nacional de Exportações 2015-2018 - PNE, que integra a política comercial brasileira, com vistas a estimular a retomada do crescimento econômico, a diversificação e a agregação de valor e de intensidade tecnológica nas exportações brasileiras (PNE, 2016). O PNE, em um contexto mais amplo, se insere em um conjunto de políticas estruturais de desenvolvimento produtivo, coordenadas pelo Governo Federal, que objetivam alavancar o crescimento econômico. A ênfase na expansão do comércio exterior se soma às iniciativas governamentais de ampliação de investimentos em infraestrutura, focada no modelo de concessões, de melhorias dos ambientes tributário e regulatório, e de desburocratização e simplificação (PNE, 2016).

O DEX, no momento da elaboração desse artigo encontra-se em sua segunda edição, com parte de seus procedimentos reavaliados, pretende apoiar um total de 200 empresas no período de 2016 a 2017. É direcionado para indústrias brasileiras que tenham a exportação como parte de sua estratégia de negócios, interessadas em desenvolver soluções em design voltadas ao mercado internacional (DEX, 2016), entendendo o design como uma ferramenta de inteligência e de promoção comercial.

A presente pesquisa procurou identificar os procedimentos adotados pelo programa e seus resultados, criando subsídios para sua melhor compreensão e permitindo, ao disponibilizar os resultados da pesquisa, sua utilização como base para futuras pesquisas e ou implementação de programas similares.

\section{DESENVOLVIMENTO}

A presente pesquisa foi desenvolvida pelos autores em parceria com o Centro Brasil Design, situado em Curitiba, mas com atuação nacional, e que coordenou a 
iniciativa. Buscou-se delinear e analisar o DEX por meio de dados documentais arquivados pelo Centro Brasil Design, além de obter dados em pesquisa de campo por meio de entrevistas com membros da equipe idealizadora, e com estudo quantitativodescritivo para buscar avaliar os impactos e a eficácia do programa. Como procedimento deve-se considerar também a participação natural dos pesquisadores que atuaram como membros do DEX, com uma observação direta intensiva e espontânea, em geral não estruturada (assistemática) enquanto observadores participantes do processo (MARCONI e LAKATOS, 2002).

O DEX seguiu os procedimentos descritos na Figura 1; sendo que nessa figura não contempla as ações de planejamento realizadas anteriormente ao início das visitações; ou seja, as ações de desenvolvimento, de planejamento estratégico e definição de ações operacionais do CBD junto com a Apex-Brasil; quando foram prédefinidas metas de visitações às empresas, quantidade de empresas por setor, précadastramento de designers e estúdios de design, além da contratação e treinamento dos facilitadores externos para comporem a equipe do CBD.

$O$ processo de desenvolvimento de produtos inovadores requer a aprendizagem organizacional no que tange à predisposição, à experimentação, visão compartilhada de produtos a serem desenvolvidos pelas equipes de projeto, além da forte convicção que as atividades de design devem ter ao centrar-se na satisfação das necessidades e desejos do usuário final. A fim de minimizar riscos, a cultura organizacional deve predispor-se a desenvolver produtos com forte ênfase nos pontos de controle (check points) e processos decisórios visando resultado satisfatório para o processo de design.

Visando facilitar o processo de inserção do design nas indústrias, o CBD aplicou a metodologia Design na Prática, de sua autoria, que possui Certidão de Registro junto ao Ministério da Cultura, Biblioteca Nacional (DESIGN NA PRÁTICA, 2013), e que permite a introdução de atividades de design nas empresas por meio de envolvimento e reconhecimento do empresariado com o tema design. A metodologia leva em consideração diversos fatores do mercado do design e dos negócios, pois de acordo com aspectos levantados em relação à evolução da gestão do design em nível nacional e internacional, é necessário familiarizar o empresário com esta atividade, visto o seu tempo escasso e desconhecimento dos benefícios diretos e indiretos desta atividade para a sua empresa. O programa DEX foi desenvolvido com base nesta metodologia objetivando, não apenas inserir o design na indústria brasileira, mas também ensinar o empresário como gerenciar e se apropriar dos processos de inovação pelo design, gerando um impacto positivo em sua cultura organizacional. 


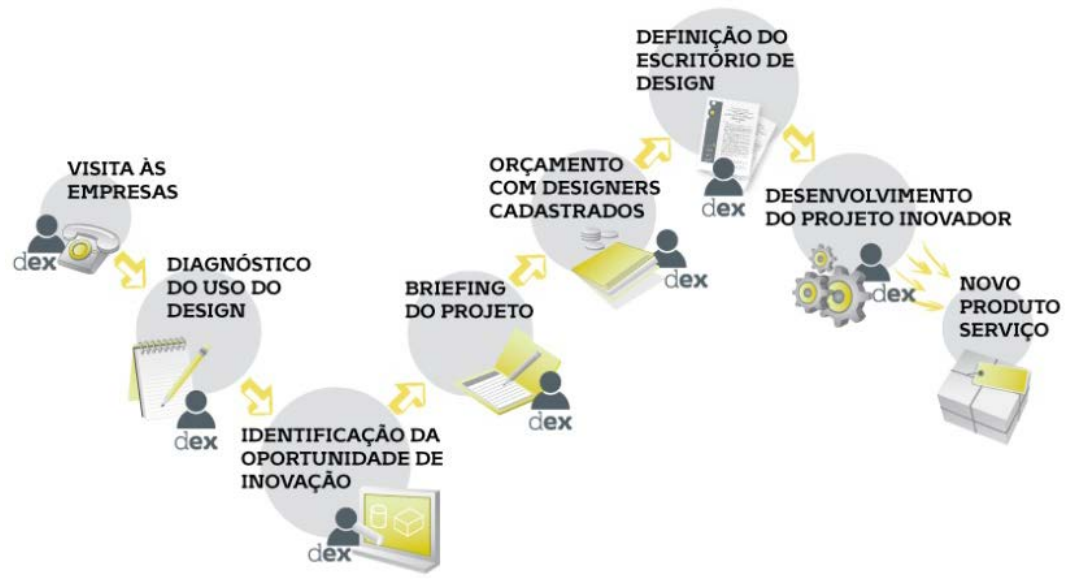

Figura 1 - Etapas do Programa Design Export - baseado na metodologia Design na Prática. Fonte: CBD (2016).

Considerando o planejamento do programa como uma fase inicial, à parte de sua execução, é possível entender o processo de execução do programa DEX como dividido em quatro etapas relativamente distintas: Visitação, Identificação de Oportunidade, Definição da Equipe (interna) ou do escritório de design (externo) responsável pelo projeto e por fim o Desenvolvimento do Projeto.

O programa contou com uma equipe de consultores técnicos, distribuídos em diferentes partes do país, responsáveis pelo atendimento direto às empresas e acompanhamento de todas as etapas do processo com a devida atenção à didática, no intuito de ensinar o empresário o como gerenciar o processo de inovação pelo design. O consultor atua como um facilitador, um intermediário ou broker, fazendo a ponte entre o empresário e o escritório de design prestador do serviço de design.

Conforme ilustrado na Figura 1 a primeira etapa corresponde a Visitação às empresas. Esta pode ser considerada uma etapa relativamente complexa para se alcançar os objetivos inicialmente planejados, pois, pelo programa deveria abranger empresas de setores distintos situados em localidades distintas em um país de dimensões continentais que é o Brasil. A equipe do CBD inicia uma fase inicial de contatos por e-mail, telefone, seguindo uma planilha de empresas por setores e também por indicação de especialistas ou pessoas referenciais em inovação e design. Esse procedimento de indicações por especialistas não segue um rigor metodológico, mas nesse caso pode ser considerado que há, em alguns momentos, certa apropriação do método Delphi, uma ferramenta de investigação qualitativa, que permite verificar convergências na identificação de empresas mais promissoras. Segue-se, posteriormente aos contatos iniciais, a fase de Visitação, que sempre vai ocorrer na própria sede da empresa, para aplicação de questionário de levantamento de dados e identificação de interesse me participar do Programa. Em paralelo a identificação das empresas mais promissoras foram realizadas palestras motivacionais no intuito de disseminar os conceitos de design para os empresários e também sensibilizá-los para adesão o programa.

Na segunda etapa é realizado individualmente o Diagnóstico do uso do design junto a cada empresa, essa ação que ocorre a partir do momento em que já se tem mapeado e identificado uma quantidade expressiva de empresas com efetivo interesse em participar do Programa. É aplicado um questionário, similar ao utilizado no 
Diagnóstico do Design Brasileiro (2014) que vai levantar um diagnóstico da situação e compreensão atual no uso do design por cada uma dessas empresas. Com base nessas informações são traçadas as estratégias para, em um processo colaborativo entre cada empresa e o CBD, buscar a identificação de oportunidades de inovação. O consultor técnico do CBD aplica ferramentas de design thinking, específicas para cada caso, culminando com a identificação de oportunidades, seleção e redação do briefing inicial do projeto.

Pode haver uma terceira etapa, caso a empresa não tenha um designer em seu quadro interno e precise de apoio para identificação e contratação dos escritórios précadastrados pelo programa, já que no caso deste programa a participação de um profissional de design é obrigatória. Com o apoio do consultor técnico do CBD a empresa identifica os possíveis prestadores de serviços que melhor se encaixam com sua demanda projetual e posteriormente definem aquele que será o prestador do serviço. As empresas devem ser definidas entre as pré-cadastradas pelo programa para poder concorrer ao subsídio disponível para apoio a contratação de designers por empresas participantes do DEX.

Como quarta etapa entende-se o Desenvolvimento do Projeto propriamente dito com foco na inovação e nas diversas abordagens do design. Nessa etapa a expertise do CBD no desenvolvimento de estratégias de inserção do design nas empresas, com a experiência acumulada na condução de programas similares, ajuda a antecipar e resolver problemas que eventualmente ocorrem entre empresa e designer no processo de desenvolvimento de projetos. O consultor técnico externo tem uma importante função de atuar como um mediador ou intermediário (broker) entre a empresa e o designer, antecipando e solucionando esses problemas. Em geral atua com ferramentas de design colaborativo, fazendo com que a equipe gestora da empresa entenda que, junto com o designer e com participação de seu cliente potencial, pode e deve participar do processo de criação de design, seja na etapa estratégica ou operacional. Nessa etapa não existe formalizada uma caixa de ferramentas de design (tool box) específica, sendo muitas das dinâmicas e métodos utilizados nos processos de design thinking e design colaborativo.

\section{RESULTADOS}

Os números significativos atingidos pela primeira edição deram visibilidade ao programa que passou a ser entendido como representativo pela mídia e por seu realizador, a Apex-Brasil, tendo assim sua segunda edição aprovada para o período de 2015 a 2017. Foram 610 empresas brasileiras sensibilizadas para o design, com 144 empresas visitadas e com 106 empresas diagnosticadas quanto ao uso do design (DESIGN EXPORT, 2016). A relevância do programa é percebida quando se verifica que do total de empresas participantes $62 \%$ nunca tinham contratado design. Esse primeiro contato e experiência do uso do design permitiu uma familiarização com os procedimentos e métodos, avaliação do impacto dessas ações no mercado, e principalmente ajudando na desmistificação do design enquanto processo de inovação.

Em termos de alcance territorial o DEX é um programa que pode ter reconhecida sua abrangência nacional, uma vez que atendeu 100 empresas em 60 cidades em 7 estados brasileiros. Como ilustra a Figura 2 é perceptível, porém que 0 alcance e participação foi preferencialmente nos estados e regiões mais 
industrializados, na região sul e sudeste, onde a demanda foi maior alinhando com o panorama apresentado pelo Diagnóstico do Design Brasileiro (2014).

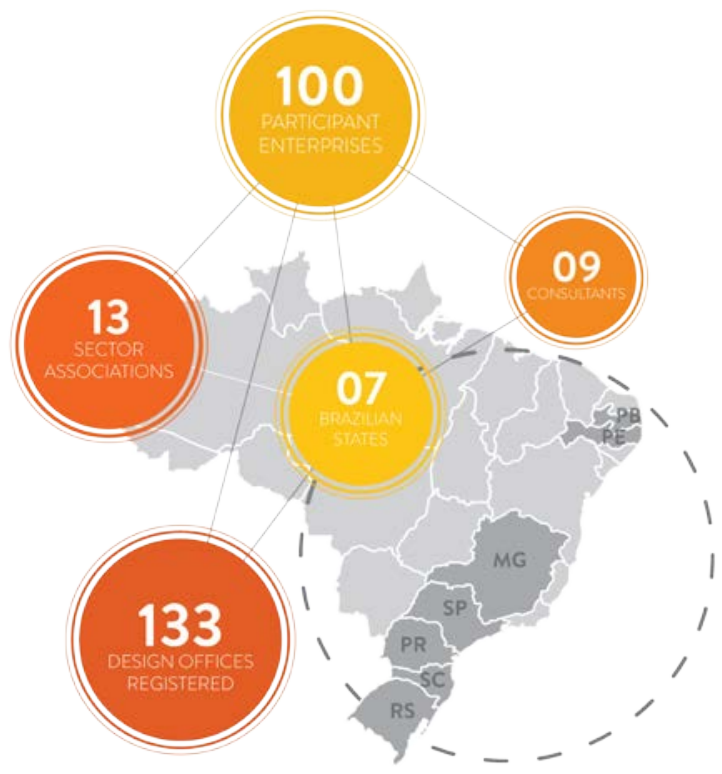

Figura 2 - Abrangência do Programa Design Export. Fonte: CBD (2016).

O porte das empresas foi variável. Participaram 13 empresas de grande porte, 39 empresas de médio porte, 31 de pequeno porte e 13 microempresas. As micro e pequenas empresas que participaram do programa não chegaram a 50\% (Figura 3) enquanto se sabe que no total de empresas no Brasil esse segmento supera $85 \%$ do total das empresas (IBPT, 2012). Esses dados evidenciam que micro e pequenas empresas ainda tem dificuldade em acessar e incorporar o design como estratégia de competitividade. A baixa participação dessas empresas também pode sugerir a necessidade de revisão da abordagem do DEX.

Por outro lado as grandes e médias empresas, que no Brasil representam menos de $15 \%$ do total (IBPT, 2012), foram representadas no DEX por mais de 54 empresas em um total de 100 . Os números apresentados corroboram também com os dados do Diagnóstico do Design Brasileiro (2014), para que se considere a possibilidade de realizar programas específicos para empresas de médio e grande porte, com maior capacidade de competir em mercados internacionais. 


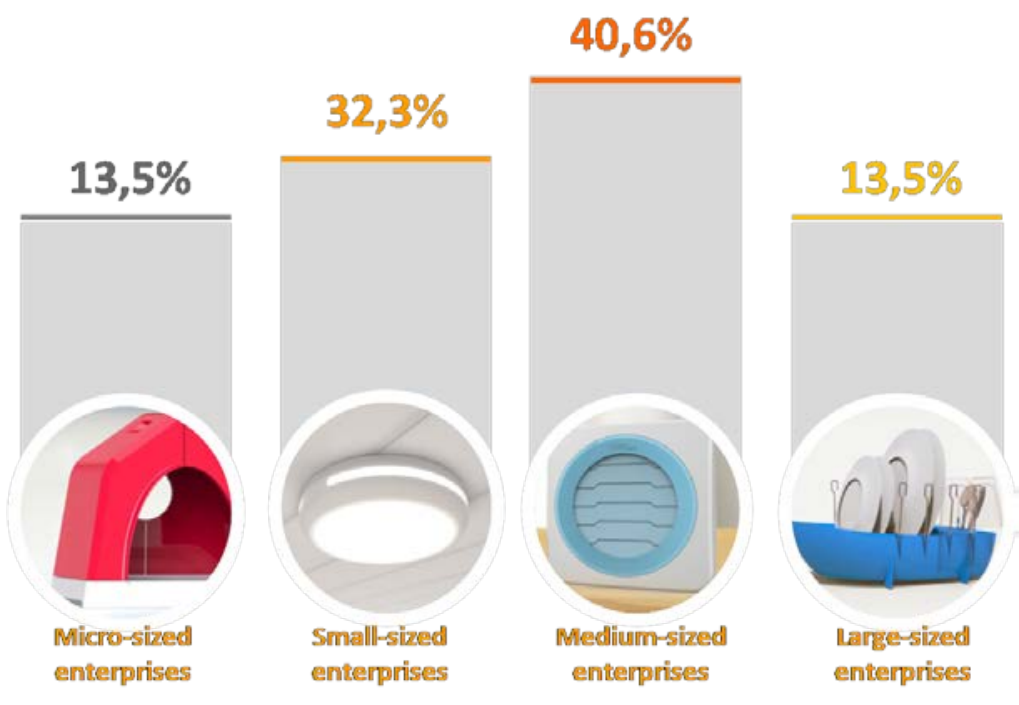

Figura 3 - Porte das empresas atendidas.

Fonte: CBD (2016).

O programa teve como foco as inovações em design, em suas diversas áreas. Como podem ser observadas na Figura 4 as ações foram preferencialmente desenvolvidas na área de novos produtos: 60,4\%; em embalagem: 15,6; em Serviços: 6,3\%; em branding e Ponto de Venda - PDV 17,7\%. Os dados apontam para a necessidade do design ser melhor compreendido pelo setor de serviços, já que proporcionalmente o setor de serviços respondia por 67,4\% do PIB no Brasil em 2013; seguindo uma tendência mundial, consolidada nos países ditos centrais e que se acelera nos países emergentes. Diferentemente do Diagnóstico do Design Brasileiro (2014) que aponta, entre os escritórios formais identificados, uma maior concentração nas áreas de Design Gráfico, Comunicação, Design Digital e Multimídia, o DEX teve maior participação na área de desenvolvimento de novos produtos.

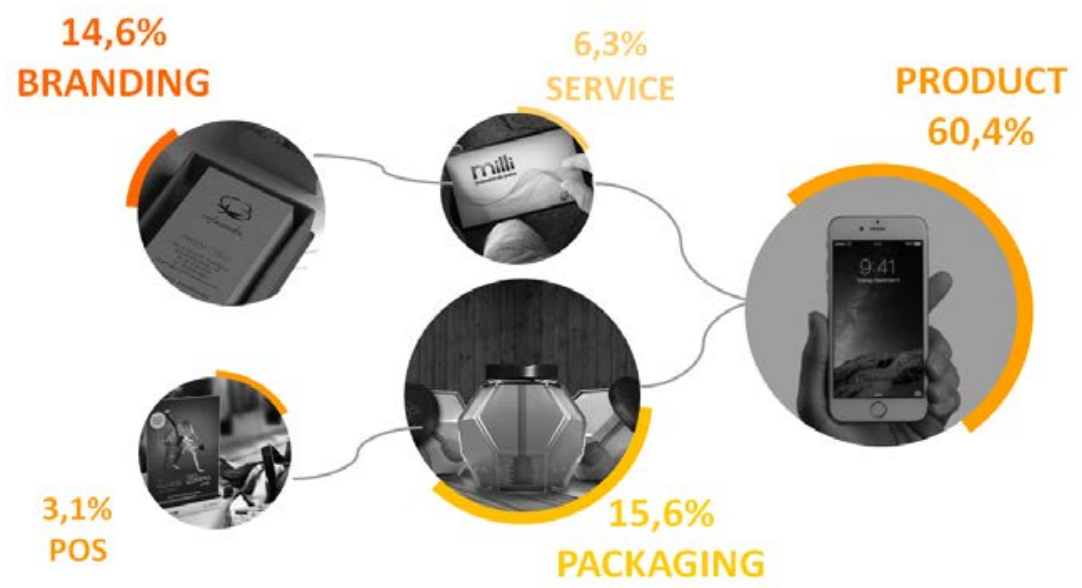

Figura 4 - foco dos projetos realizados.

Fonte: CBD (2016).

Com relação aos escritórios de design, 133 escritórios prestadores de serviço foram cadastrados das 5 regiões do país, sendo que ao final somente 40 escritórios de design foram efetivamente contratados. Os designers também foram previamente 
cadastrados uma vez que o programa previa a utilização de verbas públicas, subsidiadas para a contratação, a fundo perdido. Os designers participantes deveriam atender determinadas condições legais e técnicas. Também corroborando com o Diagnóstico do Design Brasileiro (2014) os escritórios se encontravam preferencialmente localizados nas regiões sul e sudeste.

O programa pretendeu abranger setores industriais distintos para criar uma visão mais abrangente da atuação do design. Esse objetivo foi alcançado já que ao final foram 21 setores industriais contemplados, como pode ser visto na Figura 5.
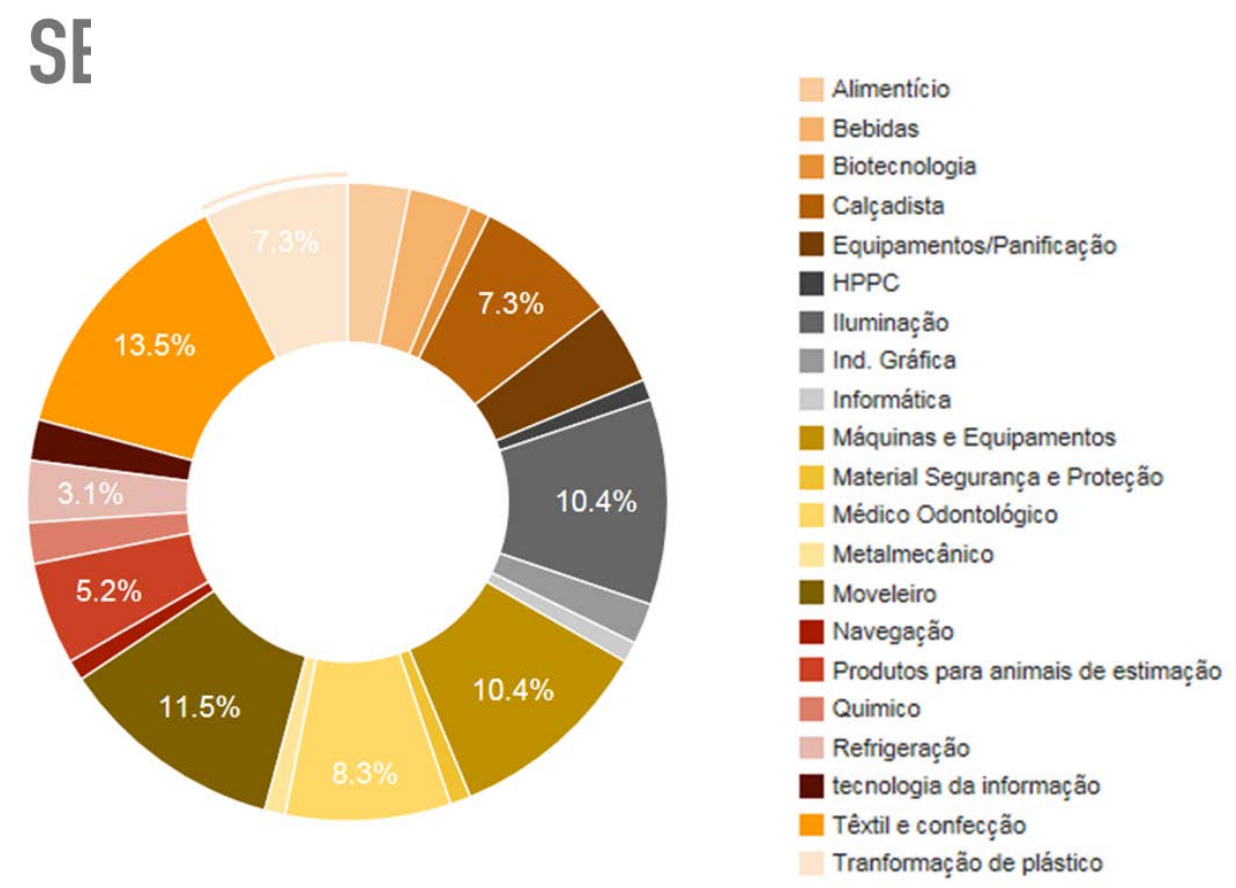

Figura 5 - Setores industriais contemplados.

Fonte: CBD (2016)

\section{CONCLUSÃO}

O Design Export apresenta-se como o amadurecimento dos programas e estratégias de promoção do Design realizados no Brasil. As ações realizadas a partir dos anos noventa dentro das políticas estabelecidas pelo Programa Brasileiro do Design e também das ações realizadas pelo Centro Brasil Design, como os programas Criação Paraná e o programa Paraná Inovador pelo Design, sugerem ser as bases e referências para o DEX.

O DEX pode contribuir para o fortalecimento da economia se inserido na cadeia produtiva brasileira, proporcionando melhores condições de competição para as empresas que almejam o mercado externo.

Os protocolos de ação do DEX estão organizados e descritos nas apostilas de treinamento com a metodologia Design na Prática, procedimento registrado na Biblioteca Nacional, porém se percebe que parte desse conhecimento pode ser classificado como conhecimento tácito, portanto não explicitáveis, o que em muitos casos pode dificultar a replicação dessas ações por terceiros. As ações e estratégias realizadas no DEX dependem do compartilhamento das práticas, através do aprender 
fazendo, da verbalização e observação, ou seja, com a participação da equipe do CBD. A participação dos membros do CBD enquanto mediadores entre os distintos atores: sejam os designers, empresários, além dos gestores dos programas e das políticas públicas, está intimamente relacionado ao sucesso do processo de gestão do DEX. Essa constatação aponta para a possibilidade de futuras pesquisas sobre o processo de gestão do conhecimento na condução de eventos dessa natureza e sobre como ocorre o processo de internalização e sociabilização, já que a identificação desses procedimentos pode vir a facilitar a sua replicação podendo vir a ser utilizado como diretriz para futuros projetos similares.

Apesar de não ser apresentado de forma explícita no programa, o modelo de gestão adotado pelo CBD se utiliza em vários momentos de uma abordagem de design colaborativo, induzindo a inserção no processo de criação de diversos atores, como por exemplo, os fornecedores e consumidores. A presença constante de facilitadores do CBD no processo de gestão, criação e avaliação, de forma colaborativa, garante ao programa um índice de sucesso superior e que o destaca de outros programas de promoção de design. No que concerne estudos futuros relacionados a esse tema, sugere-se uma investigação que identifique e esclareça o universo de ferramentas estratégicas de design colaborativo mais aplicadas no Brasil. Um estudo dessa natureza esclareceria, entre outros aspectos, as situações de aplicação e o perfil dos coordenadores.

O presente estudo mencionou dados sobre a participação dos escritórios de design cadastrados no DEX. Embora inicialmente 133 escritórios tenham sido cadastrados e 100 projetos desenvolvidos, apenas 40 escritórios foram efetivamente contratados para desenvolver soluções em design. Ou seja, diferentes escritórios de design atenderam a mais de uma empresa cliente. Essa constatação sugere que, nesse caso, houveram profissionais de design que não conseguiram convencer os seus potenciais clientes de sua competência, expertise e capacidade de colaborar para o crescimento da empresa, e também que muitos dos escritórios de design não foram efetivamente contratados por não terem atendido as exigências legais e contratuais. Do mesmo modo o dado de que $62 \%$ das empresas participantes nunca haviam contratado designers evidencia a demanda pela aplicação de programas com esse nível de impacto na indústria brasileira.

Outra constatação, que não é exclusiva do DEX, refere-se à carência de dados para o acompanhamento dos participantes após a finalização do programa; dados esses necessários para avaliação dos impactos efetivos das ações de inserção do design junto ao setor produtivo. Esse processo de acompanhamento posterior tem sido desconsiderados na maioria dos programas similares implementados no Brasil, o que aponta para a necessidade de aprimoramento estratégico. É possível que, em parte, a dificuldade se deva a falta de transparência contábil das pequenas empresas ou até uma desconfiança em disponibilizar valores de faturamento dos novos produtos para as empresas concorrentes. A superação desses desafios facilitaria o processo de avaliação do impacto da inserção do design na estratégia das empresas e, consequentemente, no processo de melhoria e adequação de futuros programas e políticas públicas de design. 


\section{REFERÊNCIAS}

ABDI. Os desafios da Política Industrial Brasileira, uma contribuição da Agência de Desenvolvimento Industrial, Brasília: ABDI, 2016 V. 1.

APEX - Design Export apresenta resultados. Disponível em:

<http://www.apexbrasil.com.br/Noticia/Design-Export-apresenta-resultados>. Acesso em 26 fev. 2016.

DESIGN NA PRÁTICA - BIBLIOTECA NACIONAL/MinC - Certificado de Registro no 619883, livro 1189, folha $288-24$ out. 2013.

CBD - Relatório interno 2016: Design Export 1a edição.

CBD - Institucional. Disponível em <http://www.cbd.org.br>. Acesso em 26 fev. 2016.

DESIGN EXPORT. Disponível em: <http://www.designexport.org.br>. Acesso em 26 fev. 2016.

DIAGNÓSTICO DO DESIGN BRASILEIRO. Disponível em <http://www.cbd.org.br/wpcontent/uploads/2013/01/Diagnostico_Design_Brasileiro_Web.pdf>. Acesso em março de 2016.

IBPT. Censo das empresas e entidades públicas e Privadas brasileiras. 2012.

Disponível em: <http://www.ibpt.com.br/img/uploads/novelty/estudo/372>. Acesso em 26 fev. de 2016.

MARCONI, Marina A.; LAKATOS, Eva M.. Técnicas de Pesquisa: Planejamento e execução de pesquisas; amostragens e técnicas de pesquisa; elaboração, análise e interpretação de dados. 5ạ edição. São Paulo: Atlas, 2002.

PATROCÍNIO, Gabriel. The impact of European design policies and their implications on the development of a framework to support future Brazilian design policies. 2013 $387 \mathrm{f}$. Tese (doutorado) - Cranfield University - School of Applied Sciences, Centre for Competitive Creative Design.

PATROCÍNIO, Gabriel. Design: Ferramenta política do século 21. REVISTA PENSAR VERDE. № 16 ano 4. mar/abr/mai 2016. Disponível em:

<https://issuu.com/pensarverde/docs/pensarverde16>. Acesso em 26 fev. 2016.

PATROCÍNIO, Gabriel; NUNES, José Mauro. Design e Desenvolvimento: 40 anos depois. São Paulo: Blucher, 2015.

PBD/MDIC - Programa Brasileiro do Design. Disponível em:

$<$ http://www.mdic.gov.br/sitio/interna/interna.php?area=2\&menu=3262>. Acesso em 18 jan. 2012.

PITCE - Diretrizes de Política Industrial, Tecnológica e de Comércio Exterior 2004.

Disponível em: <http://www.anped11.uerj.br/diretrizes.pdf>. acesso em 22 fev. 2016.

PNE - Plano Nacional de Exportações 2015-2018. Disponível em:

<http://www.desenvolvimento.gov.br/arquivos/dwnl_1435244583.pdf>. Acesso em 15 mar. 2016.

SALERNO, Mario Sergio; DAHER, Talita. Política Industrial, Tecnológica e de Comércio Exterior do Governo Federal: Balanço e Perspectivas. Brasília, setembro de 2006.

Disponível em: 
<http://investimentos.mdic.gov.br/public/arquivo/arq1272980896.pdf>. Acesso em 22 fev. 2016.

WHICHER, Anna. The value of design to business. Design for Europe. 2015. Disponível em: <http://designforeurope.eu/news-opinion/value-design-business $>$. Acesso em 23 maio 2016. 